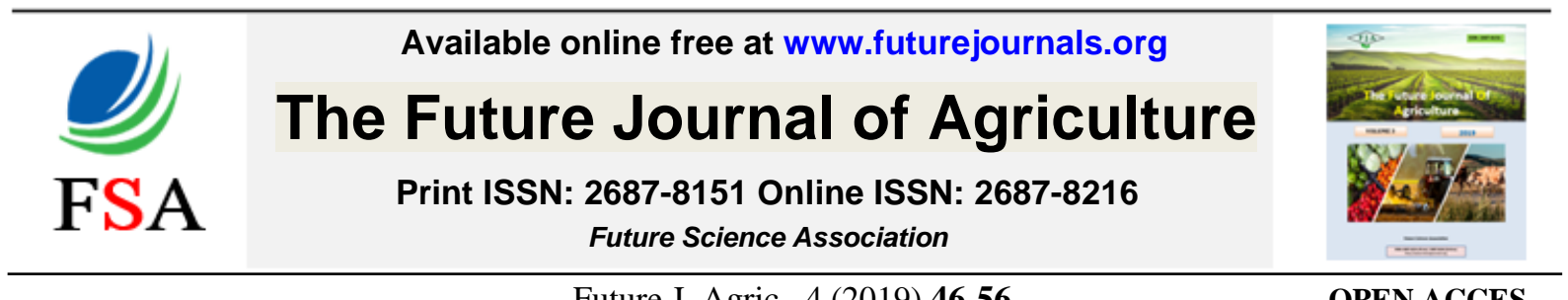

DOI: $10.37229 /$ fsa.fja.2019.12.26

Future J. Agric., 4 (2019) 46-56

OPEN ACCES

\title{
HALF-LIFE AND TOXICITY OF ORGANOPHOSPHATE AND PYRETHROID INSECTICIDES ON WHEAT GRAINS
}

\author{
Abo Arab, R.B. and Abeer A. Salem* \\ Plant Protection Research Institute, Agric. Res. Center, Dokki, Giza, Egypt. \\ *Corresponding author: medonoor200445@gmail.com Received: 10 Nov. 2019 ; Accepted: 26 Dec. 2019
}

\begin{abstract}
Toxicity and residue half-life $\left(\mathrm{RL}_{50}\right)$ of three insecticides (chlorpyrifos-methyl, pirimiphosmethyl and cyfluthrin) on wheat grains were determined through time-mortality bioassays and residue analyses on wheat grains infested with either the rice weevil Sitophilus oryzae L.), or the red flour bettle Tribolium castaneum (Herbst). Chlorpyrifos-methyl was the most toxic compound to both insect species followed by pirimiphos-methyl and cyfluthrin with median lethal concentrations $\left(\mathrm{LC}_{50}\right)$ of $0.003,0.0011 ; 0.008,0.0028$ and $0.023,0.0280 \mathrm{mg} / \mathrm{g}$ grain for the rice weevil and the red flour beetle, respectively. Cyfluthrin exhibited the greater half-life and thus the longest residual effect followed by pirimiphos-methyl and chlorpyrifos-methyl. In general, chlorpyrifos-methyl and pirimiphos-methyl exhibited greater loss of effectiveness than cyfluthrin. The results suggest that the application of the pyrethroid cyfluthrin is likely more suitable for long term storage, while the organophosphates are better suited for short term of storage. Moreover, the study suggests withholding period after post treatment is 17, 38 and more than 200 days for chlorpyrifos-methyl, pirimiphosmethyl and cyfluthrin, respectively.
\end{abstract}

Key words: Pirimiphos-methyl, chlorpyrifos-methyl, cyfluthrin, Tribolium castaneum, Sitophilus oryzae, toxicity, maximum residue limits, half-life residue.

\section{INTRODUCTION}

Cereals constitute one of the most intensely produced and consumed food products in the world. They are an important global product and an important part of the human diet as source of energy and high contents of essential fatty acids, nutritious protein, and dietary fiber; cereals also supply important minerals, vitamins, and other micronutrients that are essential for the maintenance of optimal health (Rezaei et al., 2017). Food safety is an area of growing worldwide concern on account of its direct bearing on human health. Thus, the presence of harmful pesticide residues in food is cause of concern among consumers (Kaushik $\boldsymbol{e t}$ al., 2009).

Pest control makes an important contribution to maximizing yields. There are more than 1100 pesticides currently registered on the status list of all active pesticide substances in the European Union (EU) market. Their risk to human health led to recognition of safety standards, including the allowed Maximum Residue Limits (MRLs) of pesticide residues in food products. To date, more than 17,000 MRLs have been set for the European Union encompassing various commodities for 133 active pesticide substances used either in field or store applications (Uygun et al., 2008). The environment in the storehouse and the moisture content in stored grains will affect degradation of organophosphate and pyrethroid pesticide residues on grains (Afridi et al., 2001). Pirimiphos-methyl is widely used in the major grain producing countries to protect against insect attacks, and this organophosphate insecticide has long persistence (Fleuret-lessard et al., 2007; Yu et al., 2014). The organophosphate chlorpyrifos-methyl is also commonly used as grain protectant since the 1960s (Samson et al., 1989; Daglish, 1993; Arthur, 1996).

The Acceptable Daily Intake (ADI) is the estimated amount of a substance in food (expressed on a body weight basis) that can be ingested daily over a lifetime without appreciable health risk to the consumer (Dennis and Wilson, 2003). The Estimated Daily Intake (EDI) of a pesticide residue in a given food is obtained by multiplying the 
residue level in the food by the amount of that food consumed. EDI of pesticide residues should be less than its established ADI (FAO/WHO, 2004; Darko and Akoto, 2008; WHO, 2013). The hazard risk index (HRI) is applied to assess the potential health risk from consumption of pesticide residues containing foodstuff.

MRLs are set to ensure that good agricultural practices are used to keep residues in food as low as possible and within a fate range. In most cases food with residue levels higher than the MRL are safe, but many not have been produced in the best way. Withholding interval is the time lasting between when a chemical is last used and when the food can be harvested or an animal can be slaughtered. Maximum residue limits (MRLs) of primiphosmethyl in rice have been set by the European Union $(5 \mathrm{mg} / \mathrm{kg})$, USA $(8 \mathrm{mg} / \mathrm{kg})$ and codex alimentarius commission (CAC, $7 \mathrm{mg} / \mathrm{kg}$ ) ( $\mathrm{Yu}$ et al, 2014).

The present study was conducted to evaluate the toxicity of chlopyrifos-methyl, primiphos- methyl and cyfluthrin against $S$. oryzae and $T$. castaneum adults, as well as to determine the residue half-life $\left(R_{50}\right)$ values of the three insecticides mentioned above on wheat grain and to deduce the withholding periods needed post-harvest treatment based on RL50.

\section{MATERIALS AND METHODS}

Chemical pesticides used

Chlorpyrifos- methyl

\section{Chemical formula: $\mathrm{C}_{7} \mathrm{H}_{7} \mathrm{C}_{13} \mathrm{NO}_{3} \mathrm{PS}$}

IUPAC name: $O, O$-dimethyl $O$-3,5,6-trichloro-2pyridyl phosphorothioate.

\section{Structural formula:}

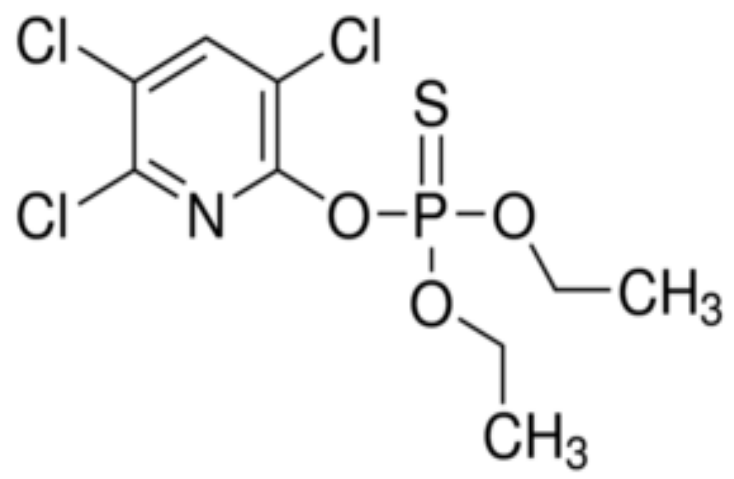

Dow Chemical Company

Trademarks: Dowco 214, Reldan and Zertell (50\% EC.).

Pirimiphos- methyl

Chemical formula: $\mathrm{C}_{11} \mathrm{H}_{20} \mathrm{~N}_{3} \mathrm{O}_{3} \mathrm{PS}$
IUPAC name: $O$-[2-(Diethylamino)-6methylpyrimidin-4-yl] $O, O$-dimethyl phosphorothioate.

Structural formula:<smiles>CCN(CC)c1nc(C)cc(OP(=S)(OC)OC)n1</smiles>

Produced by ICI Co.

Trademarks: Actellic, Blex and Silosan (50\% EC.).

\section{Cyfluthrin:}

Chemical formula: $\mathrm{C}_{22} \mathrm{H}_{18} \mathrm{Cl}_{2} \mathrm{FNO}_{3}$

IUPAC name: [(R)-cyano-[4-fluoro-3-(phenoxy) phenyl] methyl] (1R,3R)-3-(2,2 dichloroethenyl)2,2-dimethylcyclopropane-1-carboxylate.

\section{Structural formula:}

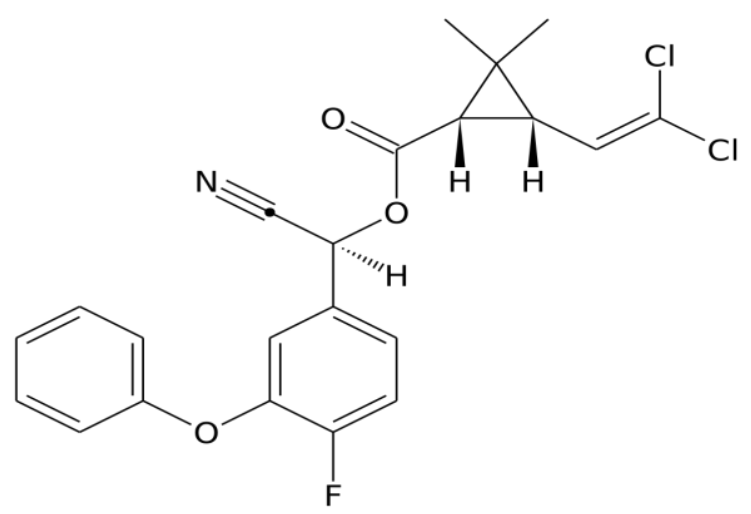

Bayer AG of West Germany. Being developed in the U.S. by Mobay chemical corp.

Trademarks: Baythroid and Bay-FCR-1272 (5\% E.C.).

\section{Insects culture}

The adults of the rice weevil, $S$. oryzae and the red flour beetles, T. castaneum were collected from Plant Protection Research Institute (PPRI), Agricultural Research Center (ARC), Sakha, Kafr El-Sheikh, Egypt. Rice weevils adults were reared on whole wheat grain while flour beetles reared on wheat flour with $5 \%$ dried yeast. The both insects were reared under laboratory conditions of $26 \pm 1{ }^{\circ} \mathrm{C}$ and $65 \pm 5 \%$ R.H. for two years in Stored Product Pests Department. Adults of 2-3 weeks old were selected for toxicity tests. 


\section{Exposure to treated wheat grains (Mixing with} feeding medium)

Batches of uninfested wheat grains (of moisture content 9\%) were weighed and placed in widemouth jars. The insecticides were diluted in water and added to the grains at rates which give the required concentrations. Five of diluted concentrations per toxicant were used to draw the toxicity lines. Jars were mechanically shaken for adequate and fixed time to ensure complete mixing process. The treated grains were allowed to dry at room temperature. For each concentration, twenty grams of treated grains were placed in a Petri dish $(9$ $\mathrm{cm}$ diameter) and this was replicated four times. Ten adults of the tested insects (2-3 weeks old) were transferred to each dish. The same numbers of insects were transferred to Petri-dishes containing non-treated grains. Mortality counts were recorded after 24 hours and corrected by Abbott's formula (1925). $\mathrm{LC}_{50}$ values were calculated by the method of Litchfield and Wilcoxon (1949).

\section{Residual toxicity assay (Persistence of bioactivity)}

Lots each of $1 \mathrm{~kg}$ wheat grain were treated with individual insecticides under investigation. Grains were weighed and placed in wide-mouth glass jars. Each insecticide was diluted in water $(50 \mathrm{ml})$ and added to the grain in which the final concentration would be equivalent to the $\mathrm{LC}_{95}$ of the insecticides to the tested insect. Jars were vigorously handshaken for adequate time to ensure complete mixing. The treated grains were allowed to dry at room temperature then packed in jute sacks $(20 \times 30 \mathrm{~cm})$ tightly closed and stored at room conditions. The treated stored grains were used in the residual toxicity and residue analysis tests. To determine the residual toxicity against the tested insects samples each of $20 \mathrm{gm}$ were withdrawn at various intervals, $1,2,3,6,10,17, \ldots$ and 327 days. At the required aging-period, triplicate $20 \mathrm{gm}$ samples were placed in Petri dishes $(9 \mathrm{~cm}$ diameter) then twenty adults of the tested insects were transferred to each dish. Exposure to the treated grains continued for 24 hours after which mortality counts were recorded. Mortality percentage were corrected according to Abbott's formula (1925). Natural mortality used in the correction was that produced when insects were exposed to untreated stored grains. The percentage of mortality for each date was plotted on normal $\mathrm{mm}$ paper and $\mathrm{LT}_{50}$ values were calculated.

\section{Chemical analysis of residues}

Residues of the tested insecticides on stored grains pretreated with $\mathrm{LC}_{95}$ were determined at each exposure time depending on the time in which the residues were still active.

\section{Extraction and clean up}

\section{Cyfluthrin}

The method used was that published by Bengston et al. (1983) with minor modifications. Samples of wheat grains each of 10 gm were ground to fine powder, transferred into conical flasks (250 $\mathrm{ml})$ and mechanically shaken with methanol (40 ml) for 3 hours. The contents were filtered and washed with methanol $(4 \times 4 \mathrm{ml})$ through Whitman filter paper No1. The filtrate and washings were combined and concentrated in a rotary evaporator at $<40^{\circ} \mathrm{C}$ to approximately $10 \mathrm{ml}$, , the methanol extract was transferred to a separating funnel; saturated sodium chloride solution $(15 \mathrm{ml})$ was added and the extract was then partitioned with hexane, $65-68{ }^{\circ} \mathrm{C}(2 \times 20$ $\mathrm{ml})$. The hexane extract was dried with anhydrous sodium sulphate before being concentrated in a rotary evaporator at $\left\langle 40^{\circ} \mathrm{C}\right.$ to approximately $1 \mathrm{ml}$., the extract was transferred to an aluminum oxide (15 gm) column. The column was washed with hexane $(10 \mathrm{ml})$ and then eluted with $20 \mathrm{ml}$ of hexane/acetone $(99+1$ by volume). The elute was concentrated in a rotary evaporator to approximately $1 \mathrm{ml}$, the volume was precisely measured and used for analysis by GLC.

\section{Pirimiphos-methyl and Chlorpyrifos-methyl}

The procedure adopted was that used by Bengston et al. (1983) for the determination of chlorpyrifos-methyl and pirimiphos-methyl residues on wheat grain. Samples of pre-treated stored wheat grains each of $10 \mathrm{gm}$ were ground to fine powder, weighed and transferred into conical flasks $(250 \mathrm{ml})$ and mechanically shaken with methanol $(40 \mathrm{ml})$ for 3 hours. The contents were filtered and washed with methanol $(4 \times 4 \mathrm{ml})$ through Whitman filter paper No1. The filtrate and washings were combined and concentrated in a rotary evaporator at $<40^{\circ} \mathrm{C}$ to approximately $4 \mathrm{ml}$. The volume of the methanolic extract was precisely measured and used for the determination of pirimiphos-methyl and chlorpyrifos-methyl by GLC. All solvents and reagents were of analytical grade.

\section{Recovery of the analysis technique}

To calculate the percent of recovery of pyrethroid, pirimiphos-methyl and chlorpyrifosmethyl, samples of non-treated stored grains were spiked with known amounts of each of the tested insecticides. Samples were performed as the same methods previously mentioned under extraction, clean up and gas chromatographic analysis. Percent of recovery was calculated by the following equation.

$\%$ Recovery $=\frac{(\mathrm{Lcs}-\mathrm{B})}{\mathrm{SA}} \times 100$

$\mathrm{Lcs}=($ Laboratory control sample) result, $\mathrm{g} / \mathrm{l}$ or $\mathrm{mg} / \mathrm{kg}$

$\mathrm{B}=$ Method blank result, $\mathrm{g} / \mathrm{l}$ or $\mathrm{mg} / \mathrm{kg}$

$\mathrm{SA}=$ Spiked added, $\mathrm{g} / \mathrm{l}$ or $\mathrm{mg} / \mathrm{kg}$ 


\section{Gas chromatographic analysis}

The GLC apparatus, model, shimadzu 4-CM equipped with flame photometric detector (FPD) was used in the determination of the organophosphate insecticides, pirimiphos- methyl and chlorpyrifos-methyl. For the pyrethroid insecticide, paythroid, GLC apparatus model, Tractor 222 equipped with Electron Capture Detector was used.

The working conditions for GLC analysis were as follows:

\section{GLC, model shimadzu 4-CM:}

- Column: SE $30+$ OV 210

- Column temperature: $200^{\circ} \mathrm{C}$

- Detector temperature: $270^{\circ} \mathrm{C}$.

- Flow rate: $30 \mathrm{ml} / \mathrm{min}$.

- Chart speed: $5 \mathrm{~mm} / \mathrm{min}$.

GLC, tractor 222:

- Detector temperature: $300^{\circ} \mathrm{C}$

- Flow rate: $35 \mathrm{ml} / \mathrm{min}$.

- Chart speed: $1 \mathrm{~cm} / \mathrm{min}$;
Under the previous conditions, pirimiohosmethyl, chlorpyrifos-methyl / and cyfluthrin showed a retention times of $1.3 \mathrm{~min} ., 1.5 \mathrm{~min}$. and $50 \mathrm{sec}$, respectively and good chromatographic separation as well as good linearity were obtained.

\section{Calibration curves of insecticides}

Series of concentrations for each insecticides was prepared in the same solvents injected with the unknown samples. A suitable aliquot was injected from each concentration at the same conditions. The insecticides resulted peak height were plotted against the $\mu \mathrm{g} / \mathrm{ml}$ of each concentration and standard curve was drawn.

\section{RESULTS}

\section{Toxicity of insecticides used}

The toxicity of the tested insecticides was determined by exposure of $T$. castaneum and $S$. oryzae to treated wheat grains. Data recorded in Table (1) showed that, insecticides can be arranged in the following descending order: chlorpyrifosemethyl > pirimiphose-methyl > cyfluthrin against $T$. castaneum. While The order of toxicity for S. oryzae had the same trend of T. castaneum.

Table 1. Toxicity of insecticides against Tribolium castaneum and Sitophilus oryzae after 24 h exposure to treated wheat grain

\begin{tabular}{lcccc}
\hline \multirow{2}{*}{\multicolumn{1}{c}{ Insecticide }} & \multicolumn{2}{c}{ Tribolium castaneum } & \multicolumn{2}{c}{ Sitophilus oryzae } \\
\cline { 2 - 5 } & LC50 (95\% FL) $(\mathbf{m g} / \mathbf{g})$ & Slope & LC50 (95\% FL) (mg/g) & Slope \\
\hline Chlorpyrifos-methyl & $0.003(0.0037-0.0025)$ & 2.60 & $0.0011(0.0384-0.0204)$ & 2.3 \\
Pirimiphos- methyl & $0.008(0.0099-0.0065)$ & 2.92 & $0.0028(0.00304-0.00257)$ & 6.7 \\
Cyfluthrin & $0.023(0.0304-0.0212)$ & 1.90 & $0.028(0.00136-0.00081)$ & 1.67 \\
\hline
\end{tabular}

\section{Residual activity of the tested insecticides (Biological analysis)}

The residual toxic action of the tested insecticides was evaluated. Residue half-life $\left(\mathrm{RL}_{50}\right)$ values are normally used in comparing the effectiveness of insecticides. Wheat grains were treated with a concentration of each insecticide which kill $95 \%$ of $T$. castaneum ( $\left.\mathrm{LC}_{95}\right)$ and stored at room conditions. Samples of grains were withdrawn at different intervals $1,2,3,6,10,17, \ldots$ and 327 days and adults of $T$. castaneum and $S$. oryzae were exposed to these samples. Percent mortality for each date was recorded in Table (2). The half-life $\left(R L_{50}\right)$ values were calculated and recorded in Table 3 . The order of the half-life of the tested insecticides against $T$. castaneum and $S$. oryzae was: cyfluthrin > pirimiphose-methyl > chlopyrifos-methyl. In general, the organophosphorous showed a greater loss of effectiveness than the pyrethroid. However, results of tested insecticides may be fell into two groups: a short residual life group including chlorpyriphos-methyl and pirimiphose -methyl and a long residual life group including cyfluthrin. 
Table 2. Corrected mortality of $T$. castaneum and $S$. oryzae confined with grain mixed with the tested insecticides

\begin{tabular}{|c|c|c|c|c|c|c|}
\hline \multirow{2}{*}{$\begin{array}{l}\text { Periods after } \\
\text { treatment } \\
\text { (days) }\end{array}$} & \multicolumn{2}{|c|}{$\begin{array}{c}\text { Chlorpyrifos-methyl } \\
(13 \mathrm{mg} / \mathrm{kg})\end{array}$} & \multicolumn{2}{|c|}{$\begin{array}{l}\text { Cyfluthrin } \\
(170 \text { mg/kg) }\end{array}$} & \multicolumn{2}{|c|}{$\begin{array}{c}\text { Pirimiphos-methyl } \\
(29 \mathrm{mg} / \mathrm{kg})\end{array}$} \\
\hline & 1 & 2 & 1 & 2 & 1 & 2 \\
\hline 1 & 90 & 90 & 100 & 90 & 100 & 100 \\
\hline 2 & 100 & 90 & 100 & 90 & 100 & 100 \\
\hline 3 & 95 & 90 & 100 & 90 & 100 & 100 \\
\hline 6 & 100 & 100 & 100 & 80 & 100 & 100 \\
\hline 10 & 95 & 100 & 85 & 90 & 100 & 100 \\
\hline 17 & 25 & 100 & 95 & 100 & 95 & 100 \\
\hline 24 & 15 & 10 & 90 & 95 & 65 & 100 \\
\hline 31 & 10 & 20 & 90 & 80 & 75 & 100 \\
\hline 38 & 5 & - & 100 & 90 & 20 & 40 \\
\hline 45 & - & 5 & 100 & 100 & - & 30 \\
\hline 60 & - & - & 100 & 80 & - & - \\
\hline 75 & - & - & 95 & 70 & - & - \\
\hline 90 & - & - & 90 & 65 & - & - \\
\hline 105 & - & - & 95 & 60 & - & - \\
\hline 120 & - & - & 95 & 70 & - & - \\
\hline 135 & - & - & 90 & 70 & - & - \\
\hline 150 & - & - & 65 & 60 & - & - \\
\hline 165 & - & - & 40 & 50 & - & - \\
\hline 180 & - & - & 40 & 50 & - & - \\
\hline 195 & - & - & 30 & 40 & - & - \\
\hline 210 & - & - & 20 & 40 & - & - \\
\hline 225 & - & - & 10 & 20 & - & - \\
\hline 240 & - & - & 10 & 20 & - & - \\
\hline 265 & - & - & 10 & 20 & - & - \\
\hline 292 & - & - & 10 & 10 & - & - \\
\hline 327 & - & - & 10 & 10 & - & - \\
\hline
\end{tabular}

Abbreviations: (1): T. castaneum; (2): S. oryzae

Table 3. Residue half-life (RL50) in days of the tested insecticides by biological and chemical assessment

\begin{tabular}{lccc}
\hline \multirow{2}{*}{ Insecticide } & \multicolumn{2}{c}{ Bioanalysis } & \multirow{2}{*}{ Chemical analysis } \\
\cline { 2 - 3 } & Sitophilus oryzae & Tribolium castaneum & \\
\hline Chlorpyrifos- methyl & 15.0 & 21.0 & 17.0 \\
Cyfluthrin & 158.0 & 165.0 & 126.0 \\
Pirimiphos- methyl & 34.5 & 36.5 & 25.0 \\
\hline
\end{tabular}




\section{Residual analysis (Chemical analysis)}

Determination of chlorpyrifos-methyl, pirimiphos-methyl and cyfluthrin residues was carried out by using gas liquid chromatographic (GLC) method. Flame photometric detector (FPD) was used for determination of the OP compounds, chlorpyrifos-methyl and pirimiphos-methyl, and an electron capture detector (ECD) was used for determination of the pyrethroid compound, cyfluthrin. Under specified gas chromatographic conditions, the three insecticides gave one peak only with a retention time of $50 \mathrm{sec}$., $1.5 \mathrm{~min}$ and $1.3 \mathrm{~min}$ for cyfluthrin, chlorpyrifos-methyl and pirimiphos-

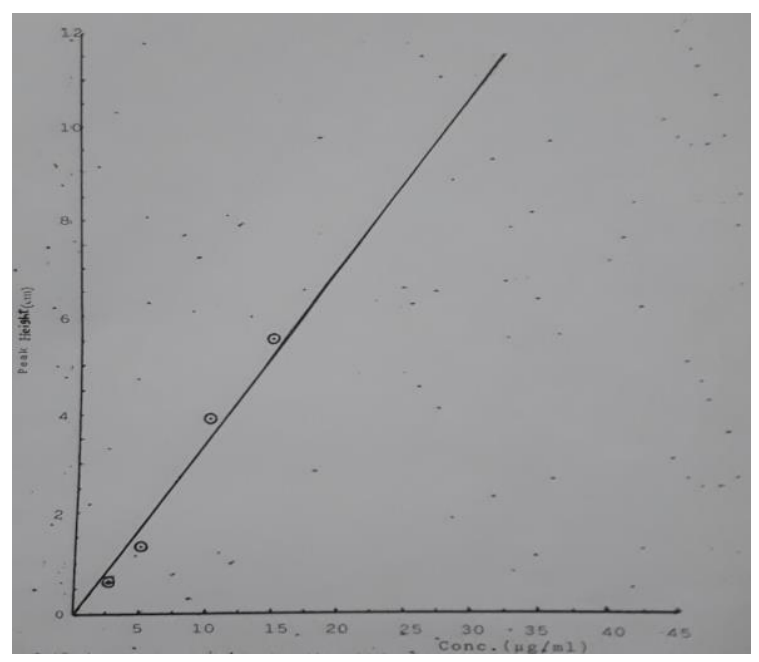

Fig. 4. Peak height in the GLC chromatogram chlorpyrifos-methyl concentration $(\mu \mathrm{g} / \mathrm{ml})$.

(Each injection represents $3 \mu$ of the indicated concentration). methyl, respectively. The calibration curves of the tested compounds were shown in Fig. (4 - 6).

The same procedures which were used for the determination of chlorpyrifos-methyl, pirimiphosmethyl and cyfluthrin in wheat grains were applied for samples fortified with known amounts from every insecticides. The percentage of recoveries of chlorpyrifos-methyl, pirimiphos-methyl and cyfluthrin were found to be $95 \%, 99 \%$, and $82 \%$, respectively. All results included in residue studies were corrected according to these percentages of recoveries.

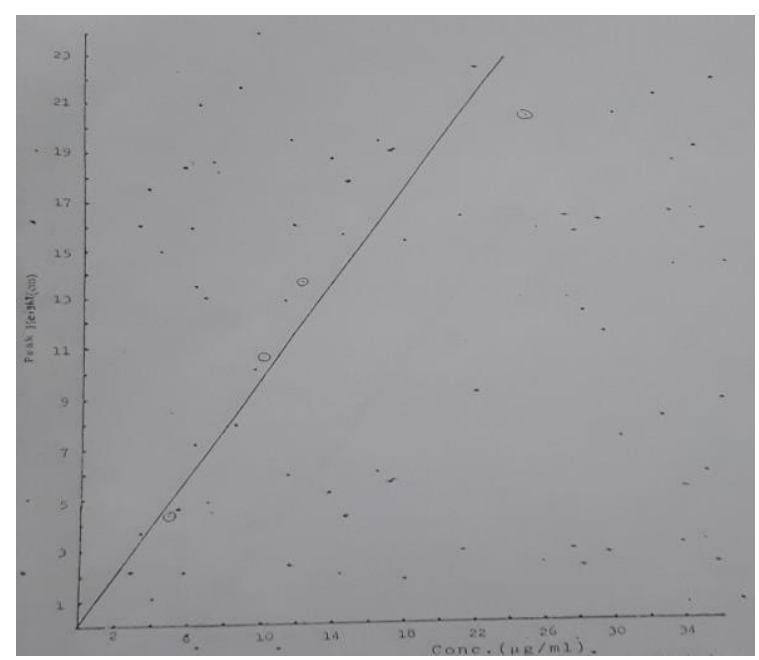

Fig. 5. Peak height in the GLC chromatogram pirimiphos-methyl concentration $(\mu \mathrm{g} / \mathrm{ml})$.

(Each injection represents $3 \mu \mathrm{l}$ of the indicated concentration).

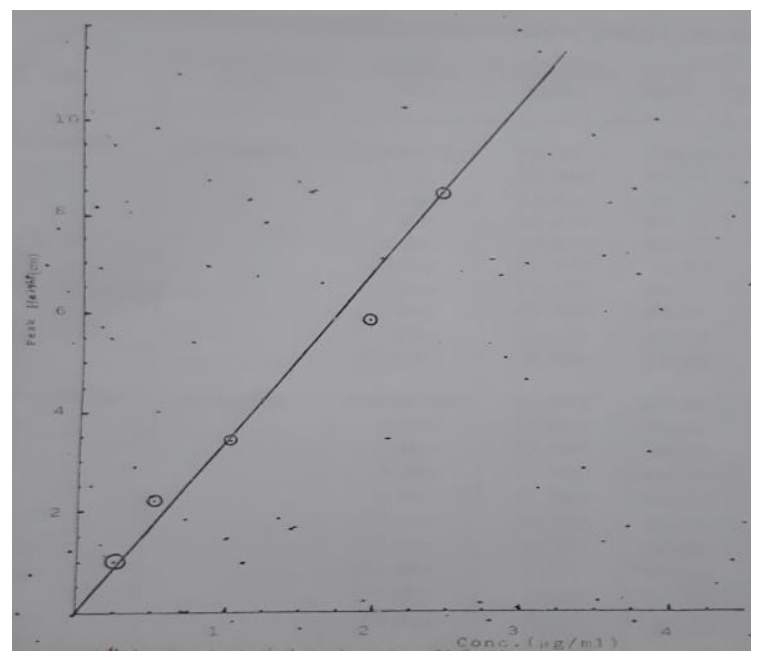

Fig. 6. Peak height in the GLC chromatogram cyfluthrin concentration $(\mu \mathrm{g} / \mathrm{ml})$. (Each injection represents $3 \mu$ of the indicated concentration). 
Chemical analysis of the treated wheat for insecticide residues one day after treatment showed that the amounts recovered were very close to the indented dosage rates (Table 4 and 5). As the tests progressed, the residue level of each insecticide showed a general decrease as shown in Table (4 and $5)$.

The rate of breakdown of chlorpyrifos- methyl and pirimiphos- methyl was significantly greater on wheat grain than the pyrethroid insecticide, cyfluthrin since their RL50 values were. 17.0 25.0 and 126.0 days, respectively. There was no wide range in the rate of breakdown of both OP compounds, chlorpyrifos- methyl and pirimiphosmethyl Table (4). These results confirm our bioassay data indicating that cyfluthrin was the most stable insecticide tested. This findings in agreement with that of Gabriel et al. (1989) and Matthews (1990). Results showed that the residues of the OP compounds in wheat grain ranged from 28.98 (day 1) to $5.56 \mathrm{mg}$ a.i./ $/ \mathrm{kg}$ (day 38) in wheat grain treated with $29 \mathrm{mg}$ a.i./kg pirimiphos- methyl and from 12.98 (day 1) to $2.63 \mathrm{mg}$ a.i./kg (day 38) in wheat grain treated with $13 \mathrm{mg}$ a.i./kg chlorpyrifosmethyl.

Table 4. Residues of Pirimiphos- methyl and Chlorpyrifos- methyl into wheat grains

\begin{tabular}{|c|c|c|c|c|c|c|}
\hline Insecticide & $\begin{array}{l}\text { Amount applied } \\
(\mathrm{mg} / \mathrm{kg})\end{array}$ & $\begin{array}{l}\text { Sampling } \\
\text { time }\end{array}$ & $\begin{array}{l}\text { Total residue } \\
\quad(\mathrm{mg} / \mathrm{kg})\end{array}$ & $\begin{array}{l}\% \text { of } \\
\text { initial }\end{array}$ & $\begin{array}{c}\text { Decline } \\
\%\end{array}$ & $\begin{array}{r}\text { RL50 } \\
\text { (days) }\end{array}$ \\
\hline \multirow{10}{*}{$\begin{array}{c}\text { Pirimipho- } \\
\text { methyl }\end{array}$} & \multirow{10}{*}{$29 \mathrm{mg} / \mathrm{kg}$} & Initial (1h.) & 29.00 & 100 & 0.00 & \multirow{10}{*}{22.6} \\
\hline & & 1 day & 28.98 & 99.93 & 0.07 & \\
\hline & & 2 days & 28.630 & 98.73 & 1.27 & \\
\hline & & 3 days & 28.624 & 98.71 & 1.29 & \\
\hline & & 6 days & 24.650 & 85.00 & 15.00 & \\
\hline & & 10 days & 21.194 & 73.10 & 26.90 & \\
\hline & & 17 days & 19.172 & 66.10 & 33.90 & \\
\hline & & 24 days & 16.320 & 56.00 & 44.00 & \\
\hline & & 31 days & 10.310 & 35.54 & 64.46 & \\
\hline & & 38 days & 5.560 & 19.20 & 80.80 & \\
\hline \multirow{10}{*}{$\begin{array}{c}\text { Chlorpyrifos } \\
\text {-methyl }\end{array}$} & \multirow{10}{*}{$13 \mathrm{mg} / \mathrm{kg}$} & Initial (1h.) & 13.00 & 100.0 & 00.12 & \multirow{10}{*}{19.6} \\
\hline & & 1 day & 12.985 & 99.88 & 00.12 & \\
\hline & & 2 days & 12.85 & 99.88 & 00.12 & \\
\hline & & 3 days & 12.782 & 98.30 & 1.70 & \\
\hline & & 6 days & 12.398 & 85.37 & 4.63 & \\
\hline & & 10 days & 10.476 & 80.70 & 19.30 & \\
\hline & & 17 days & 6.375 & 49.00 & 51.00 & \\
\hline & & 24 days & 4.867 & 37.40 & 62.60 & \\
\hline & & 31 days & 2.842 & 21.90 & 78.10 & \\
\hline & & 38 days & 2.634 & 20.20 & 79.80 & \\
\hline
\end{tabular}

Decline $\%=\frac{\text { Amount applied }- \text { Present amount }}{\text { Amount applied }} \times 100$ 
Table 5. Residue of cyfluthrin into wheat grains

\begin{tabular}{|c|c|c|c|c|c|c|}
\hline Insecticide & $\begin{array}{l}\text { Amount applied } \\
(\mathrm{mg} / \mathrm{kg})\end{array}$ & $\begin{array}{c}\text { Sampling } \\
\text { time }\end{array}$ & $\begin{array}{l}\text { Total residue } \\
(\mathrm{mg} / \mathrm{kg})\end{array}$ & $\begin{array}{l}\% \text { of } \\
\text { initial }\end{array}$ & $\begin{array}{c}\text { Decline } \\
\%\end{array}$ & $\begin{array}{l}\text { RL50 } \\
\text { (day) }\end{array}$ \\
\hline \multirow{19}{*}{ Cyfluthrin } & \multirow{19}{*}{$170 \mathrm{mg} / \mathrm{kg}$} & Initial (1h.) & 170.000 & 100.00 & 0.00 & \multirow{19}{*}{117} \\
\hline & & 1 day & 170.000 & 100.00 & 0.00 & \\
\hline & & 2 days & 170.000 & 100.00 & 0.00 & \\
\hline & & 3 days & 169.530 & 99.72 & 0.28 & \\
\hline & & 6 days & 169.012 & 99.42 & 0.58 & \\
\hline & & 10 days & 169.016 & 99.42 & 0.58 & \\
\hline & & 17 days & 168.532 & 99.14 & 0.86 & \\
\hline & & 24 days & 165.044 & 97.08 & 2.92 & \\
\hline & & 31 days & 159.070 & 93.57 & 6.43 & \\
\hline & & 38 days & 155.000 & 91.18 & 8.82 & \\
\hline & & 45 days & 151.021 & 88.84 & 11.16 & \\
\hline & & 60 days & 149.618 & 88.01 & 11.99 & \\
\hline & & 75 days & 148.019 & 87.07 & 12.93 & \\
\hline & & 90 days & 144.539 & 85.02 & 14.98 & \\
\hline & & 105 days & 141.918 & 83.48 & 16.52 & \\
\hline & & 120 days & 119.121 & 70.07 & 29.93 & \\
\hline & & 135 days & 43.225 & 25.43 & 74.57 & \\
\hline & & 150 days & 21.809 & 12.83 & 87.17 & \\
\hline & & 165 days & 19.787 & 11.64 & 88.36 & \\
\hline
\end{tabular}

Decline $\%=\frac{\text { Amount applied }- \text { Present amount }}{\text { Amount applied }} \times 100$

\section{DISCUSSION}

Present study included two items, the one to evaluate efficiency of chlorpyrifos-methyl and pirimiphos-methyl as organophosphorus and cyfluthrin as pyrethroid against two of the most important insects, $T$. castaneum and $S$. oryzae adults. The second item was to determine the residues of the tested insecticides on wheat grain biologically and chemically. The results obtained revealed that, the organophosphorus compounds were the most effective against the two tested insects and a head of them was chlorpyrifos-methyl, and pyrethroid insecticide exhibited considerable toxicity. Insecticides used in the current study may be fell into two groups, a short residual life which contain chlorpyrifos-methyl and pirimiphos-methyl, a long residual life including cyfluthrin. Furthermore, the order of the half-life of the tested insecticides against $T$. castaneum and S. oryzae was: cyfluthrin > pirimiphose-methyl > chlopyrifos-methyl. The variation of the half-life between $T$. castaneum and S.oryzae may be due to the different behavior of both insects. Some earlier studies support the obtained data, pirimipho-methyl is the most organophosphate, and deltamethrin the most common pyrethroid and both are used as chemical protectants of stored grain throughout the world (White and Leesch, 1996, Arthur and Subramanyam, 2012). Similar results were obtained by (Daglish et al., 1993) who reported that organophosphorus (fenitrothion, chlorpyrifos-methyl and pirimiphos-methyl) lost their activity during storage compared to synthetic pyrethroid compounds (permethrin and deltamethrin). Some authors have found organophosphate more efficient than pyrethroids (Arthur, 1992), while others conversely reported pyrethroids were efficient than 
organophosphates (Afridi et al., 2001; Klajic and Perci, 2009). Organophosphates are very toxic and more involved in acute poisoning than other classes of pesticides. (Collins, 2006 and Mansour, 2004). In addition, Golic et al. (2017) concluded that pirimiphos-methyl was more effective against Sitotroga Cerealella adults and had longer residual activity than cypermethrin in agreement with (Arthur, 1992). Andric et al. (2014) reported that pirimiphos-methyl was significantly more effective than the cypermethrin (combined with piperonyl butoxide). Similarly, Huang and Subramanyam (2005) reported that pirimiphos-methyl at 4, 6 and $8 \mathrm{mg} / \mathrm{kg}$ of wheat was the most effective $(100 \%)$ efficacy after 7 days of exposure of $T$. castaneum, $S$. oryzae and Polidia interpunctela while synergized pyrethrins with the piperonyl butoxide (PBO) applied at $0.38,0.75,1.13$ and $1.5 \mathrm{mg} / \mathrm{kg}$ were significantly less effective to the same species. Likewise, the current study aimed to deduce the withholding periods needed post-harvest treatment based on $\mathrm{RL}_{50}$. Results obtained showed that the rate of breakdown of chlorpyrifos-methyl and pirimiphos-methyl was significantly greater on wheat grain than the pyrethroid insecticide, cyfluthrin, since their half-life $\mathrm{RL}_{50}$ values were $17.0,25.0$ and 126.0 days, respectively. After 38 days from treatment, detected residues in wheat were below the figure of $10 \mathrm{mg} / \mathrm{kg}$ suggested for each insecticide by Codex Alimentarius Commission (1990) for cereals. Maximum residue limits (MRLs) of pirimiphos-methyl in rice have been set by the European Union $(5 \mathrm{mg} / \mathrm{kg})$, USA ( 8 $\mathrm{mg} / \mathrm{kg}$ ) and Codex Alimentariuos Commission (CAC, $7 \mathrm{mg} / \mathrm{kg}$ ) (Yu et al., 2014). This results and others would reflect chemical decay of the insecticide residues and perhaps, biological inactivation of the residues that remain (Desmarchelier, 1978, Hargreaves et al., 1982). Barakat et al. (1984) found that the half-life values of pirimiphos-methyl at room temperature were 16.8 and 15.4 days for 10 and $20 \mathrm{ppm}$, respectively. The same author also, found that the storage at constant temperature of $25^{\circ} \mathrm{C}$ prolonged the half-life values of pirimiphos-methyl to 20.3 and 19.6 days for 10 and $20 \mathrm{ppm}$, respectively. Mourkidou and Tomozou (1991) found that the time periods for the initial residue level of permethrin to be reduced by half ranged from 178 to 200,217 to 231 , and 255 day in the ground whole grain, bran and flour, respectively. Metthews and Maliphant (1993) suggest that the activity of pirimiphos-methyl is binding to some components of the grain tissue in the form of the hydrolysis products. Certainly, this was found to be the case with another organophosphorus, insecticide chlorpyrifos-methyl when applied to stored grain. The rate of loss of pesticide residues in treated wheat at monthly intervals during storage period of 52 weeks was calculated by Afridi $\boldsymbol{e t}$ al. (2001), they reported that the pyrethroid, permethrin was most stable, pirimiphos-methyl was medium stable while the organophosphate chlorpyrifos-methyl was the least stable. Bai et al. (2006) investigated organophosphorus pesticide residue in market foods including cereals in China. They also found that these residues were below the MRLs. Metthews (1990) reported that the residue of chlorpyrifosmethyl on the grain declined daily over the five months storage period, pirimiphos-methyl appeared to have the lowest rate of loss of activity. Nevertheless, Golic et al. (2017) concluded that both cypermethrin (+PBO) and pirimiphos-methyl applied at $4 \mathrm{mg} / \mathrm{kg}$ was highly effective (>94\%) against $S$. cerealella over period of 6 months, cypermethrin applied at $1.6 \mathrm{mg} / \mathrm{kg}$ was also found to be effective in protecting cereals from this stored product insect species when wheat is stored for period up to 3 months. Kaushik et al. (2016), reported that the residues of chlorpyrifos and its metabolites present in grains even 5 months of storage are not at a safe level and may pose hazards if offered for consumption without decontamination. The different results between the present study belong to the stable of tested compounds and some of the earlier studies perhaps associate with some factors such as the type of insect species, formulation of the tested compounds and conditions of the experiments carried out under it. It has been opined that the dissipation of pesticides after their application depends on various factors, including plant species, chemical formulation and application method (Ebert et al., 1999), climatic condition, physical phenomenon and chemical degradation in which sunlight plays a prominent role (Fenoll $\boldsymbol{e t}$ al., 2009). Studies on grain following post-harvest treatments with insecticides have generally shown that residues only decline rather slowly (Holland $\boldsymbol{e t}$ al., 1994; Snelson, 1987). Residues of the more lipophilic materials tend to remain on the seed coat although a proportion can migrate through to the bran and germ which contain high levels of triglyceride (Anderegg and Madison, 1983; Holland et al., 1994). Residues generally showed little decrease over 32 weeks at $20^{\circ} \mathrm{C}$ and 50-70\% relative humidity. At $30^{\circ} \mathrm{C}$, Malathion residues decreased by $30-40 \%$ while pirimiphos-methyl residues remained constant. Organochlorinic and synthetic pyrethroid residues are also very stable under silo conditions (Holland et al., 1994 Rowlands, 1975). The residual effectiveness of chlorpyrifos-methyl and pirimiphos-methyl in stored grain and their low mammalian toxicities demonstrate that these compounds are promising alternatives to Malathion, the widely used insecticide for protecting of stored grain. They can be used as a short term residual grain protectants against infestation with both $T$. castaneum and $S$. oryzae. On the other hand, the pyrethroid compound cyfluthrin, may prove to be a useful grain protectant 
for long term storage against stored product insects. Based on Maximum Residue Limits of pirimiphosmethyl in rice have been set by the European Union $(5 \mathrm{mg} / \mathrm{kg})$, USA $(8 \mathrm{mg} / \mathrm{kg})$ and codex alimentarius commission (CAC, $7 \mathrm{mg} / \mathrm{kg}$ Yu et al., 2014) and Codex Alimentarius Commission (1990) suggested $10 \mathrm{mg} / \mathrm{kg}$ for each insecticide, the present study suggests according to the data obtained that the withholding periods (PHI) for chlorpyrifos-methyl and pirimiphos-methyl after post-harvest treatment are 17 and 38 days, respectively. While the same period for cyfluthrin, is more than 200 days.

\section{REFERENCES}

Abbott, W.S. (1925). Method for computing the effectiveness of insecticides. J. Econ. Entomol., 18(2): 265-273.

Afridi, I.A.K.; Parveen, Z. and Zafar Masud, S. (2001). Stability of organophosphate and pyrethroid pesticides on wheat in storage. Journal of Stored Products Research, 37(2), 199-204.

Anderegg, B.M. and Madisen, L.G (1983). J. Economic Entomology,76,733-736.

Andrić, G.; Kljajić, P. and Pražić Golić, M. (2014). Residual efficacy of cypermethrin and pirimiphosmethyl against Sitophilus granarius (L.) and Plodia intepunctella (Hübner) on concrete surface. Pesticides and Phytomedicine, 29(4), 275281.

Arthur, F.H. (1992). Residual efficacy of chlorpyrifos-methyl + bioresmethrin and chlorpyrifosmethyl + resmethrin for controlling lesser grain borers (Coleoptera: Bostrichidae), rice weevi ls (Coleoptera: Curculionidae), and red flour beetles (Coleoptera: Tenebrionidae) in stored wheat.

Arthur, F.H. (1996). Grain protectants: current status and prospects for the future. J. Stored Prod. Res., 32(4),293-302.

Arthur, F.H. and Subramanyam, Bh. (2012). Chemical control in stored products. In Hagstrum, D.W., Philips, T.W. \& Cuperus, G. (Eds.), Stored product protection (pp 95-100).

Bai, Y.; Zhou, L. and Wang, J. (2006). Organophosphorus pesticide residues in market foods in Shaanxi area, China.Food Chem., 98:240-2.

Barakat, A.A; Kandil, M.A.; Fahmy, H.S.M. and Badawy, H.M.A. (1984). Persistence and metabolism of pirimiphos-methyl and malathion on wheat grain. Proc. Int. Conf. Env. Haz. Agrochem., Vol.;140-147.

Bengston, Mervyn; Richard, A.H.; Davies, James, M.; Desmarchelier; Ronald Henning; William
Muray; Bruce, W.; Simpson; Jack T. Snelson; Rex Sticka and Barry E. Wallbak (1983). Organo phosphorothioates and synergized synthetic phyrethroids as grain protectants on bulk wheat. Pestic. Sci., 14: 373-384

Codex Alimentarius Commissionn (1990). Joint FAO/WHO Food Standards Programme FAO, 00100 Rome, Italy. Email: codex@fao.org

Collins, D.A. (2006). A review of alternatives to organophosphorus compounds for the control of storage mites. J. Stored Prod. Res., 42(4): 395-426.

Daglish, G.J.; Hall, E.A.; Zorzetto, M.J.; Lambkin, T.M. and Erbacher, J.M. (1993). Evaluations of protectants for control of Acanthoselides obtaectus (say) (Coleoptera: Bruchidae) in navybeans (Phaseolus volgaris (L.). J. Stored Prod. Res., 29, (3): 215-219.

Darko, G. and Akoto, O. (2008). Dietary intake of organophosphorus pesticide residues through vegetables from Kumasi, Ghana. Food Chem. Toxicol., 46: 3703-3706. doi: 10.1016/j.fct.2008.09.049. [PubMed][CrossRef][Go ogle Scholar]

Dennis, M.J. and Wilson, L.A. (2003). In Encyclopedia of Food Sciences and Nutrition (Second Edition).

Desmarchelier, J.M. (1978). Mathematical examination of availability to insects of aged insecticide deposits on wheat. J. Stored Prod. Res., 14: 213-222.

Ebert, T.A.; Taylor, R.A.; Downer, R.A. and Hall, F.R. (1999). Deposit structure and efficacy of pesticide application. Interactions between deposit size, toxicant concentration and deposit number. Pesticide Science. 55: 783-792. doi: 10.1002/(SICI)1096- 9063(199908)55:83.0.COD;235 .

FAO/WHO, (2004). (Food and Agriculture Organization/World Health Organization) Food Standards Programme; Proccedings of Codex Alimentarius Commission. Twenty-Seventh Session; Geneva, Switzerland. pp. 1-103. [Google Scholar]

Fenoll, J.; Ruiz, E.; Hellín, P.; Lacasa, A. and Flores, P. (2009). Dissipation rates of insecticides and fungicides in peppers grown in greenhouse and under cold storage conditions. Food Chem., 113: 727-732.

Fleurat-Lessard, F.; Chaurand, M.; Marchegay, G. and Abecassis, J. (2007). Effects of processing on the distribution of pirimiphos-methyl residues in milling fractions of durum wheat. J. Stored Prod. Res., 43: 384-395.

Gabriel, E; Schiffers, B.C. and Verstraeten, C. (1989). Use of Ryzopertha dominica (F.) (Col., 
Bostrichidae) for the biological dosages of insecticide residues in stored products. Mededelingen Van de Faculteit Landbouwwetenschappen, Rijksuniversiteil Gent.

Golic, M.P.; Kljajic, P. and Andric, G. (2017). Residual efficacy of cypermethrin and pirimiphosmethyl against sitotroga cerealella (Olivier) in wheat grain. Pestic. Phytomed. (Belgrade), 32(3-4): 217 222.

Hargreeaves, P.A; Bengston, M. and Alder, J. (1982). Inactivation of deltamethrin on stored wheat. J. Pestic. Sci., 639-646.

Holland, P.T.; Hamilton, D. and Ohlin, B. (1994). Pesticides report 31: effects of storage and processing on pesticide residues in plant products (technical report). Pure Appl. Chem., 66(2): 335346.

Huang, F. and Subramanyam, B. (2005). Management of five stored-product insects in wheat with pirimiphos-methyl and pirimiphosmethyl plus sy nergized pyrethrins. Pest Management Science, 61(4);: 356-362. pmi d:1575101 3. doi:10.1002/ps.968

Kaushik, G.; Satya, and Naik, S.N. (2016). Pesticide Residue Dissipation storage and processing in Chickpea Legume for Food Safety. J. Adv. Food Technol. Nutr. Sci. Open, 2(2): 64-72.

Kaushik, G.; Satya, S. and Naik, S.N. (2009). Food processing a tool to pesticide residue dissipation - A review, Food Research International, 42: $26-40$.

Kljajić, P. and Perić, I. (2009). Residual effects of deltamethrin and malathion on different populations of Sitophilus granarius (L.) on treated wheat grains. J. Stored Prod. Res., 45(1), 45-48.

Litchfield, J.T.R. and Wilcoxon, F. (1949). A simpleified of evaluating dose effect experimental. J. Pharmacol. and Exp. Thresop, 96: 99-113.

Mansour, S.A. (2004). Pesticide exposure Egyptian scene. Toxicology 198: 91-115.

Matthews, W.A. and Paula Maliphant (1993). The fate and insecticidal activity of pirimiphos-methyl in stored wheat grain. Pest. Sci., 37: 93-97.
Matthews, W.A. (1990). The fate of chlorpyrifosmeyhyl in stored wheat: A comparesion of laboratory -scale experiment with a pilot -scale treatment Pestic. Sci., 30: 21-29.

Mourkidou-Papadopoulou, $\mathbf{E}$ and Tomazou, $\mathbf{T}$. (1991). Persistence and activity of permethrin in stored wheat and its residues in wheat milling fractions. J. Stored Prod. Res., 27(4): 249-254.

Rezaei, M.; Shariatifar, N.; Shoeibi, S.; Ahmadi, M.A. and Khaniki, G.J. (2017). Simultaneous Determination of Residue from 58 Pesticides in the Wheat Flour Consumed in Tehran, Iran by GC/MS. Iranian J. Pharmaceutical Res., 16(3): 1048-1058.

Rowlands, D.G. (1975). Metabolism of insecticides on grains. Residue Review,58,113-155.

Samson, P.R.; Parker, R. J. and Jones, A.L. (1989). Laporatory studies on prorections for conrol of S. oryzae (Coleopteran: Curculionidae) and Ryzopertha dominica (Coleoptera: Bostrichidae) in paddy rice. J. Stored Prod. Res., 25(1): 39-48.

Snelson, J.T. (1987). Grain protestants ACIAR monograph series. (Australian) (Vol.3, pp .448p). Canberra. Australia; Australian Center for International Agricultural Research.

Uygun, U.; Senoz, B., and Koksel, H. (2008). Dissipation of organophosphorus pesticides in wheat during pasta processing. Food Chemistry, 109: 355360 .

White, N.D.G. and Leesch, J.G. (1996). Chemical control. In B. Subramanyam \& D.W. Hagstrum (Eds.), Integrated management of insects in stored products. (pp. 287-330). NewYork-Basel-Hong Kong: Marcel Dekker.

WHO, (2013). (World Health Organization) Guidelines for Predicting Dietary Intake of Pesticide Residues (Revised). Available:online http://www.who.int/foodsafety/pub lications/chem/en/pesticide_en.pdf.

Yu, C.; Li, Y.; Zhang, Q.; Zou, N.; Gu, K.; Li, X. and Pan, C. (2014). Decrease of pirimiphos-methyl and deltamethrin residues in stored rice with postharvest treatment. Int. J. Environ. Res. Public Health,11(5): 5372-5381. 